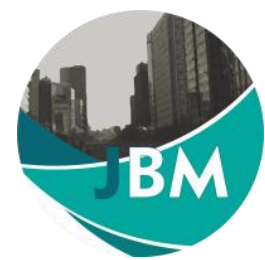

\title{
CORPORATE SOCIAL RESPONSIBILITY, GOOD CORPORATE GOVERNANCE, DAN NILAI PERUSAHAAN: KINERJA KEUANGAN SEBAGAI MEDIATOR
}

Submitted Date :

1 September 2020

Accepted Date :

16 September 2020
Rian Surachmad

Universitas Merdeka Malang

surachmadrian.aiesec@yahoo.com

Umu Khouroh*

Universitas Merdeka Malang

umu.khouroh@unmer.ac.ld

Suggested Citation:

Huang, C.-J. (2010). Corporate governance, corporate social responsibility and corporate performance. Journal of Management \& Organization, 16(5), 641-655.

\begin{abstract}
:
This study purpose to examine the impact of Corporate Social Responsibility (CSR) and Good Corporate Governance (GCG) on Firm Value with the mediator variable is Financial Performance. The samples used were 15 companies included in The Indonesia Most Trusted Company on Investors and Analysts Assessment Survey. The analytical method used the path analysis and hypotheses testing used SEM-PLS method. The results showed that CSR and GCG do no direct impact on firm's value, on the contrary it had a positive impact on financial performance. Another finding is that financial performance has a direct effect on firm value thereby indicated the role of fully mediation in the relationship between CSR and GCG with firm value. For companies included in the group of The Indonesia Most Trusted Companies on Investors and Analysts Assessment Survey, the expansion of CSR and GCR information further strengthens the image that has an impact on increasing firm value. This empirical evidence reinforces the argument that companies need to do CSR and GCG to drive performance improvements which in turn will affect the firm value.
\end{abstract}

Keywords : Corporate Social Responsibility, Good Corporate Governance, Financial Performance, Firm Value

Abstrak:

Penelitian ini bertujuan untuk menguji dampak Corporate Social Responsibility (CSR) dan Good Corporate Governance (GCG) terhadap Nilai Perusahaan dengan mediator variable Kinerja Keuangan. Sampel yang digunakan adalah 15 perusahaan yang termasuk dalam kelompok The Indonesia Most Trusted Company on Investors and Analysts Assessment Survey. Metode analisis menggunakan metode analisis jalur dan alat pengujian hipotesis menggunakan metode SEM-PLS. Hasil penelitian menunjukkan bahwa CSR dan GCG tidak berdampak langsung terhadap nilai perusahaan sebaliknya berdampak positif signifikan terhadap kinerja keuangan. Temuan lain adalah bahwa kinerja keuangan berpengaruh langsung terhadap nilai perusahaan sehingga menunjukkan peran mediasi penuh dalam dalam hubungan antara CSR dan GCG dengan nilai perusahaan. Bagi perusahaan yang termasuk dalam kelompok The Indonesia Most Trusted Company on Investors and Analysts Assessment Survey perluasan informasi CSR dan GCR semakin memperkuat citra yang berdampak pada peningkatan nilai perusahaan. Bukti empiris ini memperkuat argumen bahwa perusahaan perlu melakukan CSR dan GCG untuk mendorong peningkatan kinerja yang pada gilirannya akan mempengaruhi nilai perusahaan.

Kata Kunci : Corporate Social Responsibility, Good Corporate Governance, Kinerja Keuangan, Nilai Perusahaan

JEL Classification: G32, G34

${ }^{*}$ Corresponding Author 


\section{Latar Belakang}

Theory of the firm memberikan penjelasan mengenai peningkatan nilai perusahaan yang menjadi tujuan pendirian perusahaan (Brigham \& Houston, 2006; Salvatore, 2005). Nilai perusahaan dipengaruhi oleh informasi keuangan perusahaan (Tandelilin, 2010), yang diyakini dapat menggerakkan pasar dan bisnis (Lev \& Gu, 2016). Fama (1978) menjelaskan bahwa nilai perusahaan dicerminkan oleh harga saham. Tolok ukur meningkatnya nilai perusahaan berangkat dari kapasitas untuk mengoperasionalisasikan perusahaan dan mencapai target laba. Laba menjadi unsur penting dalam menciptakan nilai perusahaan dan mengindikasikan capaian penting perusahaan pada masa yang akan datang. Kemampuan menciptakan laba dari asset yang dimiliki menjadi penentu nilai perusahaan (Modigliani \& Miller, 1958). Dengan laba yang diperoleh, pemegang saham mendapatkan deviden, pertumbuhan perusahaan meningkat dan kelangsungan hidup perusahaan dapat dipertahankan. Banyak hasil penelitian menjelaskan bahwa meningkatnya kinerja keuangan akan meningkatkan nilai perusahaan (Ulupui, 2007; Carlson \& Bathala, 1997).

Tanggung jawab terhadap peningkatan nilai perusahaan yang dicerminkan oleh kondisi keuangan bukan satusatunya pijakan operasionalisasi perusahaan, namun juga harus berpijak pada aspek lingkungan dan sosial (Nurlela \& Islahuddin, 2008). Pijakan ini mengharuskan perusahaan untuk memberikan informasi tentang Corporate Social Responsibility (CSR). CSR membuat perusahaan memperoleh keuntungan jangka panjang dengan munculnya kepercayaan yang terjalin antara stakeholder dengan perusahaan (Susanto, 2009). Kajian empirik tentang hubungan CSR dengan nilai perusahaan memberikan hasil yang bervariasi. Beberapa temuan menunjukkan bahwa perilaku etis CSR meningkatkan nilai perusahaan (Wang et al., 2016; Jo \& Harjoto, 2011; Paul \& Barbara, 2009). Sebaliknya penelitian lainnya menunjukkan bahwa CSR menurunkan nilai perusahaan (Vicente et al., 2011; Becchetti et al., 2012) dan tidak berdampak pada nilai perusahaan (Liu \& Zhang, 2017; Aras et al., 2010)

Perkembangan perusahaan selain menuntut perusahaan untuk menerapkan CSR juga mengharuskan pengelolaan yang memisahkan antara kepemilikan dan manajemen perusahaan (Berle dan Mean, 1932) dan menjadi awal kemunculan konsep Corporate Governance (CG) (Denis \& McConnell, 2003). Teori keagenan menjelaskan potensi konflik yang mungkin timbul ketika pengelolaan perusahaan diserahkan oleh pemilik kepada pihak manajemen (Jensen, 1993). Prinsip Good Corporate Governance (GCG) menjadi alat untuk meminimalkan konflik sehingga tujuan perusahaan tercapai (Fama, 1980). Midiastuti \& Machfoedz (2003) menjelaskan bahwa salah satu cara penerapan GCG adalah melalui kepemilikan manajerial yang menjadi dorongan bagi pihak manajemen untuk menjalankan apa yang menjadi kepentingan shareholders. Kepemilikan manajerial yang semakin meningkat menjadi insentif pihak manajemen dalam memaksimalkan kepentingan shareholders. Pihak manajemen dalam hal ini juga mendapatkan manfaat dengan mendapatkan keuntungan dari perolehan laba perusahaan. Beberapa kajian empirik tentang pengaruh GCG terhadap nilai perusahaan memberikan temuan yang bervariasi. Temuan penelitian mengkonfirmasi peran GCG dalam meningkatkan nilai perusahaan (Klapper \& Love, 2002; Connelly et al., 2012; Villanueva-Villar et al., 2016; Ararat et al., 2017). Sebaliknya penelitian lainnya menunjukkan bahwa GCG menurunkan nilai perusahaan (Becchetti et al., 2012; Vicente et al., 2011) juga tidak memberi dampak signifikan pada nilai perusahaan (Liu \& Zhang, 2017; Aras et al., 2010).

Kontradiksi dan ketidakkonsistenan hasil penelitian empiris sebelumnya mengenai dampak CSR dan GCG pada nilai perusahaan, memberikan celah untuk dilakukan pengujian kembali dalam konteks Indonesia. Selain itu, beberapa penelitian empiris yang melibatkan Nilai perusahaan, Kinerja Keuangan, GCG juga CSR dengan menjadikan CSR dan GCG sebagai moderator memberikan bukti bahwa CSR dan GCG bukan moderator hubungan kinerja keuangan dengan nilai perusahaan (Nuriwan, 2018; Muliani et al., 2014). Dalam penelitian ini CSR dan GCG dijadikan driven bagi peningkatan kinerja keuangan yang selanjutnya akan mendorong peningkatan nilai perusahaan. Dalam hal ini kinerja keuangan dijadikan mediator dalam hubungan antara CSR dan GCG dengan nilai perusahaan dengan fokus pada perusahaan yang termasuk kategori The Indonesia Most Trusted Company On Investors and Analysts Assessment Survey, karena memiliki penilaian tersendiri sehubungan dengan praktik CSR dan GCG dan bagaimana dampak kedua variabel tersebut pada nilai perusahaan.

\section{Kajian Literatur dan Pengembangan Hipotesis}

\section{CSR dan Nilai Perusahaan}

UU No. 40 Tahun 2007 menguraikan bahwa penerapan CSR menjadi keharusan bagi perusahaan yang operasionalisasinya dibidang yang terkait dengan sumber daya alam (SDA). Keberadaan lingkungan sosial menuntut 
perusahaan untuk menerapkan CSR. Perusahaan bertanggung jawab untuk meningkatkan laba dan mengembalikannya sebagian untuk masyarakat ketika menggunakan sumber daya manusia (SDM) dan komunitas. Daniri (2008) menjelaskan bahwa kelahiran CSR merupakan desakan masyarakat agar perusahaan tidak hanya fokus pada peningkatan laba dan meningkatkan kesejahteraan shareholders, yang seringkali abai terhadap tanggung jawab sosial dengan melakukan eksploitasi SDA, perusakan lingkungan dan lainnya. Tuntutan stakeholder dan lingkungan memaksa perusahaan untuk menjalankan CSR dengan harapan memperoleh respon yang baik dari stakeholder sehingga nilai perusahaan semakin meningkat.

World Business Council in Sustainable Development (WBCSD) memberikan definsi CSR sebagai bentuk kesediaan perusahaan untuk berperilaku etis dan berkontribusi bagi pembangunan ekonomi yang berkelanjutan dengan meningkatkan taraf hidup pegawai, komunitas di sekitarnya serta masyarakat. Perhatian terhadap lingkungan kerja, lingkungan sekitar, investasi sosial dan masyarakat menjadi cara perusahaan mengimplementasikan CSR, sehingga meningkatkan image dan kinerja keuangan. Definisi CSR menurut Robins (2005) merupakan konsep yang mana perusahaan secara sukarela melakukan integrasi permasalahan lingkungan dan sosial dalam aktivitas bisnis dan hubungan dengan stakeholder dengan melakukkan tindakan yang bertanggung jawab secara sosial. Van der Wiele et al. (2001) mendefinisikan CSR sebagai kewajiban perusahaan untuk memanfaatkan sumber dayanya terlepas dari keuntungan yang diperoleh dengan cara yang memberikan manfaat bagi masyarakat, melalui partisipasinya sebagai bagian dari masyarakat, memperhatikan masyarakat luas, serta meningkatkan kesejahteraan masyarakat. Kesimpulannya adalah bahwa CSR menjadi bagian dari bisnis, mementingkan stakeholder untuk memberikan kemanfaatan atau kesejahteraan masyarakat.

Saat ini, CSR tidak hanya dilihat sebagai cost center namun juga menjadi strategi untuk mendorong dan menjaga kestabilan pertumbuhan perusahaan dalam jangka panjang. Ataur (2001) menguraikan bahwa perusahaan harus menaruh perhatian pada kepentingan stakeholder untuk mencapai keberlangsungan hidup jangka panjang. Investor memberikan penilaian bagus pada perusahaan yang menaruh perhatian dan aktif menjalankan CSR. Banyak bukti menunjukkan adanya dampak positif CSR dengan nilai perusahaan (Hudoyo \& Juniarti, 2015; Wang et al., 2016; Jo \& Harjoto, 2011; Cheung et al., 2010; Paul \& Barbara, 2009). Fontaine et al. (2006) menguraikan bahwa CSR dengan sebagai alat untuk mendapatkan lisensi operasi (teori legitimasi) agar diakui oleh masyarakat dan tidak dianggap sebagai pemangsa lingkungan dan sosial. Aktivitas CSR yang mengutamakan kepentingan stakeholder dan legitimasi masyarakat akan mampu meningkatkan reputasi agar dapat menjaga keberlanjutan operasi sehingga nilai perusahaan meningkat dimata investor dan kreditor. Oleh karena itu rumusan hipotesisnya adalah:

\section{$H \mathrm{H}$ : CSR meningkatkan nilai perusahaan.}

\section{GCG dan Nilai Perusahaan}

Definisi GCG menurut The Indonesian institute for corporate governance (IICG) (2010) merupakan struktur, sistem, dan proses yang dipakai unsur-unsur perusahaan guna memberi value-added yang berkelanjutan dalam jangka panjang (www.iicg.org). GCG didorong oleh krisis ekonomi yang melanda dunia, sehingga dikembangkan struktur dan sistem operasi perusahaan yang lebih baik agar krisis tidak terulang kembali. GCG mengharuskan suatu perusahaan mengimplementasikan sistem dan struktur tertentu (Daniri, 2008).

Lebih lanjut (Daniri, 2008) menjelaskan bahwa kemunculan GCG dikarenakan adanya upaya untuk memisahkan pengelolaan dan kepemilikan perusahaan dengan memberikan kewenangan manajer/direksi (pengelola) untuk menjalankan dan membuat keputusan atas nama pemilik. Principal-agency theory yang menjadi dasar pemisahan tersebut mendorong manajemen untuk meningkatkan keuntungan pribadinya dibanding tujuan perusahaan. Tuntutan perusahaan agar memperoleh kinerja dan memiliki tata kelola yang baik medorong aplikasi GCG. GCG menurut Setyapurnama \& Norpratiwi (2012) menjadi alat untuk memastikan bahwa manajemen melakukan tindakan terbaik bagi kepentingan perusahaan.

Implementasi GCG memberikan keyakinan bahwa perusahaan mampu mendorong terciptanya suasana yang kondusif dan menjadi dasar operasionalisasi perusahaan secara lebih baik, efisien dan menguntungkan. Saat ini shareholder aktif memantau kinerja perusahaan dengan anggapan bahwa meningkatnya return karena meningkatnya GCG (Coombes \& Watson, 2000).Barnhart \& Rosenstein (1998) menyatakan bahwa peningkatan GCG sejalan dengan peningkatan nilai perusahaan. Black et al. (2006) menguraikan bahwa dengan pengelolaan yang lebih baik, perusahaan menjadi lebih menguntungkan sehingga pemegang saham memperoleh dividen yang lebih tinggi sekaligus memberikan informasi bagi investor bahwa earnings atau dividen lebih tinggi jika perusahaan 
mengimplementasikan GCG dengan lebih baik. Efektivitas GCG dalam jangka panjang dapat memberikan keuntungan bagi pemegang saham dan meningkatkan kinerja.

Secara umum tujuan GCG adalah penciptaan value added bagi stakeholder, yang dijadikan Global Corporate Governance sebagai isu penting dunia. GCG menjdi mesin pertumbuhan global, bertanggungjawab dalam penyedian pekerjaan, pelayanan privat dan publik, pengadaan barang dan jasa serta infrastruktur. Komite Nasional Kebijakan Governance (KNKG) (2006) menguraikan karakter GCG meliputi: transparancy, accountability, responsibility, independency, dan fairness yang diharapkan membantu perusahaan mencapai tujuannya. Peningkatan nilai perusahaan menjadi salah satu tujuan GCG (IICG). Bukti empirik menunjukkan GCG memberi dampak positif pada nilai perusahaan (Klapper \& Love, 2002; Connelly et al., 2012; Villanueva-Villar et al., 2016; Ararat et al., 2017). Oleh karena itu rumusan hipotesisnya adalah:

H2: GCG meningkatkan nilai perusahaan.

\section{CSR, GCG, Kinerja Keuangan dan Nilai Perusahaan}

Aktivitas perusahaan merupakan sumber informasi bagi pihak eksternal atau investor bagi pengambilan keputusan dalam mengalokasikan sumber daya mereka untuk perusahaan (Mahon, 2002). Aktivitas CSR merupakan upaya perusahaan untuk meningkatkan image dan memperoleh legitimasi (Fontaine et al., 2006). Evan \& Freeman (1988) menyatakan bahwa kinerja keuangan perusahaan bergantung pada kesediaan stakeholder untu memberikan sumber daya sesuai dengan persepsi mereka terhadap aktivitas dan reputasi perusahaan. Sebagai pemilik dana, investor akan selalu melakukan pemantauan terhadap investasinya agar memberikan keuntungan sesuai yang dharapkan. Implementasi CSR membuat perusahaan memperoleh keuntungan jangka panjang dengan munculnya kepercayaan yang terjalin antara stakeholder dengan perusahaan (Susanto, 2009). Gantino (2016) dan Prasetyo \& Meiranto (2017) memberikan bukti bahwa CSR berdampak positif pada nilai perusahaan.

Moug (2011) berpendapat bahwa peningkatan akuntabilitas pengelolaan dana perusahaan dengan GCG akan membuat investor percaya dan mendorong peningkatan kinerja yang gilirannya meningkatkan nilai perusahaan. Riana \& Stanly (2014), Coombes \& Watson (2000) dan Huang (2010) menunjukkan bahwa CG meningkatkan kinerja perusahaan. Midiastuti \& Machfoedz (2003) menjelaskan bahwa salah satu cara penerapan GCG adalah melalui kepemilikan manajerial yang menjadi dorongan bagi pihak manajemen untuk menjalankan apa yang menjadi kepentingan shareholders. Kepemilikan manajerial yang semakin meningkat menjadi insentif pihak manajemen dalam memaksimalkan kepentingan shareholders. Pihak manajemen dalam hal ini juga mendapatkan manfaat dengan mendapatkan keuntungan dari perolehan laba perusahaan.

Tuntutan perusahaan agar memperoleh kinerja dan memiliki tata kelola yang baik medorong aplikasi GCG (Daniri, 2008). Saat ini shareholder aktif memantau kinerja perusahaan dengan anggapan bahwa meningkatnya return karena meningkatnya GCG (Coombes \& Watson, 2000) dan meningkatnya kinerja keuangan akan meningkatkan nilai perusahaan (Nuriwan, 2018; Yendrawati \& Pratidina, 2013; Ulupui, 2007; Carlson \& Bathala, 1997). Berdasarkan uraian tersebut, rumusan hipotesisnya adalah:

H3: CSR meningkatkan kinerja keuangan.

H4: GCG meningkatkan kinerja keuangan.

H5: kinerja keuangan meningkatkan nilai perusahaan.

H6a: Kinerja keuangan mediator hubungan CSR dengan nilai perusahaan.

H6b: Kinerja keuangan mediator hubungan GCG dengan nilai perusahaan.

\section{Metode Penelitian}

Populasi penelitian ini adalah perusahaan yang termasuk kategori The Indonesia Most Trusted Company On Investors and Analysts Assessment Survey", dengan alasan karena perusahan-perusahaan tersebut memiliki penilaian tersendiri sehubungan dengan praktik CSR dan memenuhi kriteria GCG. Periode waktu analisis 2014-2016 sehingga diperoleh jumlah sampel 15 perusahaan. Kriteria pengukuran CSR menggunakan CSRI, GCG diwakili oleh kepemilikan manajerial, kinerja keuangan diwakili oleh Return On Equity (ROE) dan Tobin'Q mewakili nilai perusahaan. Pengujian hipotesis menggunakan pendekatan SEM-PLS.

Hasil Penelitian 


\section{Statistik Deskriptif}

Tabel 1 menjelaskan bahwa dari 15 perusahaan sampel, nilai GCG berada dalam rentang antara 0,0001 sampai dengan tertinggi 0,0112 yang dicapai oleh PT. Gudang Garam. Kisaran nilai CSR antara 0,4286 sampai dengan tertinggi 0,7473 yang dicapai oleh PT. Indofood Sukses Makmur. Kisaran nilai ROE antara -0,1048 sampai dengan tertinggi 1,3212 yang dicapai oleh PT. Unilever. Sedangkan kisaran nilai perusahaan antara 0,5483 sampai dengan tertinggi 9,5395 yang dicapai oleh PT. Unilever.

Tabel 1. Deskripsi Variabel

\begin{tabular}{lcccr} 
Perusahaan & GCG & CSR & ROE & Tobins'Q \\
\hline GGRM & 0.0112 & 0.6593 & 0.1662 & 1.3661 \\
ASII & 0.0004 & 0.5714 & 0.1460 & 1.0676 \\
BBCA & 0.0016 & 0.5385 & 0.2141 & 0.7185 \\
BMRI & 0.0007 & 0.5055 & 0.1565 & 0.5730 \\
TLKM & 0.0006 & 0.4505 & 0.2564 & 1.4192 \\
UNVR & 0.0036 & 0.6923 & 1.3212 & 9.5395 \\
BBNI & 0.0001 & 0.5385 & 0.1406 & 0.5483 \\
ISAT & 0.0005 & 0.4286 & -0.0430 & 0.6681 \\
KLBF & 0.0001 & 0.5385 & 0.1976 & 4.4440 \\
INDF & 0.0005 & 0.7473 & 0.2585 & 1.1450 \\
GIAA & 0.0020 & 0.4945 & -0.1048 & 2.2910 \\
SMGR & 0.0028 & 0.5824 & 0.1787 & 1.8544 \\
ADHI & 0.0003 & 0.4835 & 0.1036 & 0.6682 \\
HMSP & 0.0035 & 0.6484 & 0.4838 & 9.0799 \\
APLN & 0.0002 & 0.6264 & 0.1112 & 0.5519 \\
\hline
\end{tabular}

\section{Pengujian Hipotesis}

\section{Outer Model}

Hasil penilaian outer model terhadap indikator formatif variabel nilai perusahaan, kinerja keuangan, GCG dan CSR semuanya menunjukkan $p$ value $<0,05$ dan nilai $\mathrm{VIF}<5$ yang artinya model konstruk formatif dinilai layak.

\section{Inner Model}

Pengujian Inner model guna memastikan structural model yang dibentuk akurat dan robust dengan menggunakan 3 kriteria:

\section{Goodness of Fit}

Hasil uji goodness of fit memberikan gambaran bahwa model struktural yang dibangun memenuhi kriteria kelayakan model dengan nilai: $A P C=0.352, \quad P=0.003 ; \quad A R S=0.574, \quad P=<0.001 ; \quad A A R S=0.548, \quad P=<0.001 ; \quad A V I F=1.426$; $A F V I F=1.956 ;$ GoF 0.758; SPR=1.000; RSCR=1.000; $S S R=1.000$ dan NLBCDR=1.000.

\section{Nilai R2 dan Q2}

Nilai R2 menguraikan kemampuan determinasi variabel eksogen terhadap endogennya. Tabel 2 memperlihatkan bahwa nilai R2 untuk konstruk kinerja keuangan adalah 0,453. Artinya CSR dan GCG mampu menjelaskan kinerja keuangan mampu sebesar 45,3\%. Nilai R2 untuk konstruk nilai perusahaan 0,695 yang artinya bahwa kemampuan CSR, GCG dan kinerja keuangan menjelaskan nilai perusahaan sebesar $69,5 \%$. Nilai R2 kinerja keuangan tersebut termasuk dalam kategori moderat atau sedang dikarenakan 0,67>0,453>0,33 dan Nilai R2 nilai perusahaan masuk kategori tinggi karena 0,695 >0,67.

Tabel 2.Nilai R2 dan Nilai R2 Adjusted dan Q2 pada konstruk

\begin{tabular}{crcr} 
Konstruk & Nilai R2 & Nilai R2 Adjusted & \multicolumn{1}{c}{ Nilai Q2 } \\
\hline Kinerja Keuangan & 0,453 & 0,425 & 0,521 \\
Nilai Perusahaan & 0,695 & 0,671 & 0,710 \\
\hline
\end{tabular}


Nilai Q2 (predictive relevance) digunakan untuk pengujian model struktural yaitu menentukan baik buruknya nilai amatan dan estimasi parameternya. Q2 $>0$ berarti model mempunyai kemampuan prediktif, Q2 $<0$ berarti model tidak punya kemampuan prediktif. Perhitungan Q2 sebagai berikut : Nilai Q2 sebesar 0,672 >0 sehingga CSR, GCG dan kinerja keuangan mempunyai kemampuan dalam memprediksi nilai perusahaan.

Tabel 3. Hasil Pengujian Hipotesis

\begin{tabular}{llcrrl} 
& Hipotesis & Nilai Koefisien Jalur & P-values & Effect Size & Hasil Hipotesis \\
\hline H1 & CSR $\rightarrow$ NP & 0,129 & 0,192 & 0,071 & Ditolak \\
H2 & GCG $\rightarrow$ NP & 0,198 & 0,085 & 0,121 & Ditolak \\
H3 & CSR $\rightarrow$ KK & 0,415 & 0,001 & 0,130 & Diterima \\
H4 & GCG $\rightarrow$ KK & 0,398 & 0,002 & 0,131 & Diterima \\
H5 & KK $\rightarrow$ NP & 0,623 & $<0,001$ & 0,119 & Diterima \\
H6a & CSR $\rightarrow$ KK $\rightarrow$ NP & 0,258 & 0,006 & 0,142 & Diterima \\
H6b & GCG $\rightarrow$ KK $\rightarrow$ NP & 0,247 & 0.008 & 0,152 & Diterima \\
\hline
\end{tabular}

Keterangan: CSR= Corporate Social Responsibility, GCG=Good Corporate Governance, KK=Kinerja Keuangan, $\mathrm{NP}=$ Nilai Perusahaan.

Tabel 3 memberikan informasi mengenai nilai koefisien jalur CSR $\rightarrow$ NP sebesar 0,129 dengan $p$-values 0,192 > 0,05 yang berarti bahwa $\mathrm{H} 1$ ditolak, CSR tidak memberi dampak pada NP. Pada hubungan antara GCG dengan NP nilai koefisien jalur 0,198 dengan $p$-values $0,085>0,05$ yang artinya bahwa $\mathrm{H} 2$ ditolak, GCG tidak berdampak pada NP. Pada hubungan antara CSR dengan KK nilai koefisien jalur 0,415 dengan p-values $0,001<0,05$ yang artinya $\mathrm{H} 3$ diterima, CSR berdampak positif pada KK. Pada hubungan antara GCG dengan KK nilai koefisien jalur 0,398 dengan p-values 0,002 $<0,05$ yang artinya bahwa H4 diterima, GCG berpengaruh positif pada KK. Pada hubungan antara KK dengan NP nilai koefisien jalur 0,623 dengan $p$-values $<0,001<0,05$ yang artinya bahwa H5 diterima, GCG berpengaruh positif pada NP. Hasil uji pengaruh tidak langsung nilai kofisien jalur CSR $\rightarrow K K \rightarrow N P$ sebesar 0,253 dengan $\mathrm{p}$-values $0,006<0,05$ yang disimpulkan bahwa $\mathrm{H6a}$ diterima artinya KK memediasi hubungan CSR dengan NP. Pengujian pengaruh tidak langsung lainnya nilai kofisien jalur CSR $\rightarrow K K \rightarrow N P$ sebesar 0,247 dengan $p$-values $0,008<0,05$ yang disimpulkan bahwa H6b diterima artinya KK memediasi hubungan GCG dengan NP.

\section{Pembahasan}

\section{Pengaruh CSR terhadap Nilai Perusahaan}

Berdasarkan hasil uji statistik, diperoleh informasi bahwa CSR tidak berdampak terhadap nilai perusahaan. Temuan tersebut memberikan dukungan terhadap penelitian Liu \& Zhang (2017) dan Aras et al. (2010). Secara konseptual, informasi implementasi CSR menjadi pedoman investor dalam melakukan investasi (Basalamah \& Jermias, 2005). Temuan ini mengindikasikan bahwa investor mengabaikan pengungkapan CSR perusahaan karena adanya jaminan dalam UU yang mengharuskan perusahaan melakukan CSR dan mengungkapkannya, jika tidak, perusahaan mendapatkan sanksi sesuai dengan ketentuan tersebut.

Temuan ini juga sejalan dengan temuan Agustine (2014), bahwa CSR yang tidak berdampak pada nilai perusahaan disebabkan beberapa kondisi antara lain kecenderungan investor mengabaikan pegungkapan CSR, pengungkapan CSR yang masih rendah dan secara langsung variabel CSR tidak bisa diukur serta berharap mendapatkan capital gain sebagaimana dijelaskan Tandelilin (2010) yang menyatakan bahwa alasan investor melakukan pembelian saham, adalah mendapatkan tiga hal yaitu: capital gain; dividen; hak suara dan ikut memberikan andil dalam aktivitas perusahaan. Faktanya, ada kecenderungan investor membeli saham guna memperoleh capital gain yang sifatnya jangka pendek, sedangkan CSR adalah strategi untuk mempertahankan kelangsungan hidup jangka panjang. Dampak CSR bersifat jangka panjang yang mengakibatkan investor abai terhadap kegiatan CSR perusahaan.

\section{Pengaruh GCG terhadap nilai perusahaan.}


Hasil analisis statistik, diperoleh informasi bahwa GCG tidak berdampak pada nilai perusahaan. Manajer memiliki saham dalam jumlah yang relatif kecil dan menunjukkan resiko manajer sebagai pemegang saham relatif kecil. Kebijakan manajer akan berbeda dengan manajer yang juga pemegang saham. Regulasi yang ada membatasi kepemilikan tersebut, sehingga menyebabkan GCG tidak berdampak signifikan. Kepemilikan manajerial dianggap akan memberi preseden buruk terhadap kondisi perusahaan karena memungkinkan terjadinya ekspropriasi (penggunaan kendali untuk meningkatkan kesejahteraan individu dari distribusi kekayaan pihak lain).

\section{CSR, GCG terhadap Kinerja Keuangan.}

Hasil uji statistik memberikan bukti bahwa CSR berdampak signifikan terhadap kinerja keuangan. Pengungkapan CSR yang semakin luas membuat kinerja keuangan meningkat. Pengungkapan CSR memberikan sinyal positif kepada stakeholders atau shareholders yang akan mendorong peningkatan minat investor untuk menanamkan modal yang dibutuhkan untuk kegiatan operasionalisasi perusahaan agar laba semakin meningkat. Temuan ini mendukung hasil penelitian Gantino (2016) dan Prasetyo \& Meiranto (2017). Penelitian ini juga memberikan bukti empirik bahwa GCG berdampak pada kinerja keuangan. Temuan ini mendukung temuan Riana \& Stanly (2014) yang mengemukakan bahwa GCG berdampak pada peningkatan kinerja keuangan. Penerapan GCG yang semakin baik akan mendorong peningkatan kinerja. Penerapan GCG di perusahaan peraih The Indonesian Most Trusted Company terbukti mampu mendongkrak kemampuan perusahaan dalam menghasilkan profitabilitas sehingga kinerja meningkat. Selain itu proses pengawasan kepemilikan manajerial mampu berjalan baik sehingga berpengaruh terhadap return yang dibuktikan dengan kontribusi GCG dalam peningkatan kinerja keuangan.

\section{Pengaruh Kinerja Keuangan terhadap Nilai Perusahaan.}

Hasil perhitungan statistik memberikan bukti empirik bahwa kinerja keuangan memberikan dampak peningkatan nilai perusahaan. Kinerja keuangan yang semakin meningkat menjadi pendorong meningkatnya nilai perusahaan. Temuan ini medukung penelitian Nuriwan (2018), Yendrawati \& Pratidina (2013) dan Ulupui (2007). Kemampuan perusahaan untuk meningkatkan laba akan berpengaruh pada peningkatan harga saham dalam lebih lanjut meningkatkan nilai perusahaan. Prospek perusahaan akan meningkat jika keuntungan meningkat sehingga menjadi pendorong bagi investor untuk menaikkan investasinya dalam saham perusahaan. Pemantauan investor terhadap kinerja keuangan dengan melihat kinerja perusahaan dalam menghasilkan return sebagai indikasi semakin meningkatnya produktivitas perusahaan. Kinerja keuangan menjadi alat manajemen untuk bertanggung jawab terhadap stakeholder dan mencapai tujuan perusahaan.

\section{Kinerja Keuangan dapat memediasi hubungan CSR terhadap Nilai Perusahaan.}

Hasil uji statistik memberikan bukti bahwa kinerja keuangan menjadi mediator hubungan CSR dengan nilai perusahaan. Semakin meluas pengungkapan CSR akan menjadi pendorong dalam meningkatkan kinerja keuangan, yang akhirnya nilai perusahaan meningkat. Laporan keuangan yang mengungkapkan tingginya profitabilitas dan pelaksanaan CSR setidaknya menjadi pertimbangan investor. Melalui pengungkapan CSR, akuntabilitas dan asimetri informasi akan berkurang. Pelaporan CSR akan memberikan informasi kepada stakeholders mengenai pelaksanaan tanggung jawab sosial perusahaan. Wang et al. (2016) menjelaskan bahwa CSR memberi dampak positif pada perusahaan. Image perusahaan di mata stakeholders melalui tindakan peduli terhadap sosial lingkungan, akan mendorong peningkatan penjualan yang pada gilirannya akan meningkatkan laba. Kegiatan CSR dapat menjamin keberlangsungan hidup perusahaan dalam jangka panjang. Apresiasi konsumen terhadap perusahaan yang melakukan CSR dalam bentuk pembelian produk dengan harapan sebagian laba yang disisihkan berguna bagi kepentingan lingkungan sosial, antara lain membangun fasilitas masyarakat, beasiswa, program pelestarian lingkungan dan lainnya.

\section{Kinerja Keuangan dapat memediasi hubungan GCG terhadap Nilai Perusahaan.}

Hasil uji statistik juga memberikan bukti bahwa kinerja keuangan menjadi mediator hubungan GCG dengan nilai perusahaan. Investor menyadari bahwa tata kelola yang baik akan menjadi pendorong perusahaan dalam menghasilkan laba. Kemampuan perusahaan meningkatkan kinerja tercermin pada harga saham. Peningkatan harga saham, mendorong kenaikan return sebagai akibat implementasi GCG. Moug (2011) berpendapat bahwa peningkatan 
akuntabilitas pengelolaan dana perusahaan dengan GCG akan membuat investor percaya dan mendorong peningkatan kinerja yang gilirannya meningkatkan nilai perusahaa. Tuntutan perusahaan agar memperoleh kinerja dan memiliki tata kelola yang baik medorong aplikasi GCG. Saat ini shareholder aktif memantau kinerja perusahaan dengan anggapan bahwa meningkatnya return karena meningkatnya GCG dan meningkatnya kinerja keuangan akan meningkatkan nilai perusahaan.

\section{Kesimpulan}

Temuan penelitian ini menjelaskan bahwa perusahaaan peraih The Indonesian Most Trusted Company melaksanakan CSR untuk tujuan memberdayakan masyarakat sekaligus promosi. Artinya dukungan stakeholders menjadi penentu bagi eksistensi perusahaan. Pengungkapan CSR menjadi pertimbangan investor dan akan meningkatkan nilai tambah dari kepercayaan yang didapat sehingga memberi dampak positif pada nilai perusahaan. Hermawan (2014) menjelaskan bahwa selain respon pasar yang tertuju pada alokasi dana CSR perusahaan, kinerja keuangan juga menjadi salah satu faktor penentu nilai perusahaan. Desakan lingkungan memberikan tuntutan kepada perusahaan untuk memaksimalkan nilai perusahaan dengan meningkatkan akuntabilitas dan transparansi pelaporan kinerja perusahaan. Perusahaan dapat memaksimalkan nilai, reputasi, dan dalam jangka panjang mampu mempertahankan kelangsungan hidup dengan melakukan CSR.

Hasil analisis statistik juga memberikan bukti bahwa kinerja keuangan juga mediator hubungan GCG dengan nilai perusahaan. Tata kelola yang baik dianggap penting bagi para investor karena dapat meningkatkan laba. Bagi investor, hal terpenting adalah bagaimana perusahaan mampu meningkatkan kinerja yang tergambar pada peningkatan harga saham. Meningkatnya harga saham, meningkatkan return yang mereka dapatkan sebagai dampak pelaksanaan GCG. Implikasi praktis penelitian ini adalah masalah keagenan dan kepemilikan dapat diminimalisir dengan pelaksanaan praktik transparansi dalam RUPS berkala dan penerapan praktik Blockchain di dalam perusahaan. Perusahaan perlu mengungkapkan CSR secara konsisten agar meningkatkan nilai perusahaan. Selanjutnya penelitian mendatang dapat dilakukan dengan memperluas lingkup penelitian dengan menambah indikator dalam setiap variabel penelitian juga menambah periode penelitian untuk mengetahui dampak CSR yang merupakan program jangka panjang perusahaan.

\section{Daftar Pustaka}

Ararat, M., Black, B. S., \& Yurtoglu, B. B. (2017). The effect of corporate governance on firm value and profitability: Time-series evidence from Turkey. Emerging Markets Review, 30, 113-132. https://doi.org/https://doi.org/10.1016/j.ememar.2016.10.001

Aras, G., Aybars, A., \& Kutlu, O. (2010). Managing corporate performance Investigating the relationship between. International Journal of Productivity and Performance Management, 59(April 2016), 229-254. https://doi.org/10.1108/17410401011023573

Ataur, R. B. (2001). A study of corporate social disclosures inBangladesh. Managerial Auditing Journal, 16(5), 274289. https://doi.org/10.1108/02686900110392922

Barnhart, S. W., \& Rosenstein, S. (1998). Board Composition, Managerial Ownership, and Firm Performance: An Empirical Analysis. Financial Review, 33(4), 1-16. https://doi.org/10.1111/j.1540-6288.1998.tb01393.x

Basalamah, A. S., \& Jermias, J. (2005). Social And Environmental Maintaining Organizational Legitimacy ? Gadjah Mada International Journal of Business, 7(1), 109-127.

Becchetti, L., Ciciretti, R., Hasan, I., \& Kobeissi, N. (2012). Corporate social responsibility and shareholder's value. Journal of Business Research, 65(11), 1628-1635. https://doi.org/https://doi.org/10.1016/j.jbusres.2011.10.022

Black, B. S., Love, I., \& Rachinsky, A. (2006). Corporate Governance Indices and Firms ' Market Values : Time Series Evidence from Russia. Emerging Markets Review, 7, 361-379.

Brigham, E. F., \& Houston, J. F. (2006). Dasar-dasar manajemen keuangan, edisi 11. Jakarta: Salemba Empat.

Carlson, S. J., \& Bathala, C. T. (1997). Ownership Differences and Firms' Income Smoothing Behavior. Journal of Business Finance \&amp; Accounting, 24(2), 179-196. Retrieved from https://econpapers.repec.org/RePEc:bla:jbfnac:v:24:y:1997-03:i:2:p:179-196 
Cheung, Y. L., Tan, W., Ahn, H.-J., \& Zhang, Z. (2010). Does Corporate Social Responsibility Matter in Asian Emerging Markets? Journal of Business Ethics, 92(3), 401-413. https://doi.org/10.1007/s10551-009-0164-3

Connelly, J. T., Limpaphayom, P., \& Nagarajan, N. J. (2012). Form versus substance: The effect of ownership structure and corporate governance on firm value in Thailand. Journal of Banking \&amp; Finance, 36(6), 1722-1743. https://doi.org/:10.1016/j.jbankfin.2012.01.017

Coombes, P., \& Watson, M. (2000). Three surveys on corporate governance. THE McKINSEY QUARTERLY, (April), $74-77$

Daniri, M. A. (2008). Standarisasi tanggung jawab sosial perusahaan.

Denis, D. K., \& McConnell, J. J. (2003). International Corporate Governance. Journal of Financial and Quantitative Analysis, 38(1), 1-36. Retrieved from https://econpapers.repec.org/RePEc:cup:ffinqa:v:38:y:2003:i:01:p:1-36_00

Evan, W. M., \& Freeman, R. E. (1988). A stakeholder theory of the modern corporation: Kantian capitalism. In T. L. Beauchamp \& N. E. Bowie (Eds.), Ethical theory and business (3rd ed, pp. 97-106). Retrieved from http://images.lib.monash.edu.au/mgc1020/04143123.pdf

Fama, E. F. (1978). The Effects of a Firm's Investment and Financing Decisions on the Welfare of Its Security Holders. The American Economic Review, 68(3), 272-284. Retrieved from www.jstor.org/stable/1805260

Fama, E. F. (1980). Agency Problems and the Theory of the Firm. Journal of Political Economy, 88(2), 288-307. Retrieved from www.jstor.org/stable/1837292

Fontaine, C., Haarman, A., \& Schmid, S. (2006). The Stakeholder Theory.

Gantino, R. (2016). Pengaruh Corporate Social Responsibility Terhadap Kinerja Keuangan Perusahaan Manufaktur yang Terdaftar di Bursa Efek Indonesia periode 2008-2014. Jurnal Dinamika Akuntansi Dan Bisnis, 3(2), 17-31. https://doi.org/10.17969/jdab.v3i2.5384

Hermawan, S. (2014). Pengaruh Kinerja Keuangan terhadap Nilai Perusahaan dengan Pengungkapan Corporate Social Responsibility sebagai Variabel Pemoderasi. Jurnal Dinamika Akuntansi, 6(2). https://doi.org/10.15294/jda.v6i2.3250

Huang, C.-J. (2010). Corporate governance, corporate social responsibility and corporate performance. Journal of Management \& Organization, 16(5), 641-655. https://doi.org/DOI: 10.1017/S1833367200001784

Hudoyo, O., \& Juniarti. (2015). Pengaruh Corporate Social Responsibility Terhadap Nilai Perusahaan Pada Sub Sektor Industri Metal, Pakan Ternak, Kertas dan Kayu yang Terdaftar di BEl 2009-2013. Business Accounting Review, 3(2), 121-130.

Jensen, M. C. (1993). The Modern Industrial Revolution, Exit, and the Failure of Internal Control Systems. The Journal of Finance, 48(3), 831-880. https://doi.org/10.1111/j.1540-6261.1993.tb04022.x

Jo, H., \& Harjoto, M. A. (2011). Corporate Governance and Firm Value: The Impact of Corporate Social Responsibility. Journal of Business Ethics, 103(3), 351-383. https://doi.org/10.1007/s10551-011-0869-y

Klapper, L. F., \& Love, I. (2002). Corporate Governance, Investor Protection, and Performance in Emerging Markets (No. 2818). https://doi.org/dx.doi.org/10.2139/ssrn.303979

KNKG. (2006). Pedoman Umum Good Corporate Governance Indonesia. Komite Nasional Kebijakan Governance, Jakarta.

Lev, B., \& Gu, F. (2016). The end of accounting and the path forward for investors and managers. John Wiley \& Sons.

Liu, X., \& Zhang, C. (2017). Corporate governance, social responsibility information disclosure, and enterprise value in China. Journal of Cleaner Production, 142, 1075-1084. https://doi.org/https://doi.org/10.1016/j.jclepro.2016.09.102

Mahon, J. F. (2002). Corporate Reputation: Research Agenda Using Strategy and Stakeholder Literature. Business \& Society, 41(4), 415-445. https://doi.org/10.1177/0007650302238776

Midiastuti, P. P., \& Machfoedz, M. (2003). Analisis Hubungan Mekanisme Corporate Governance Dan Indikasi Manajemen Laba. Simposium Nasional Akuntansi (SNA) KE VI Surabaya, 16 - 17 Oktober 2003, 176-199.

Modigliani, F., \& Miller, M. H. (1958). The Cost of Capital, Corporation Finance and Theory of Investment. The American Economic Review, 48(3), 261-297.

Moug, P. (2011). Decisions, dilemmas and deliberation: exploring the legitimacy of the organisation and design of a stakeholder workshop in an environmental research project. Local Environment, 16(2), 129-145. https://doi.org/10.1080/13549839.2011.557354 
Muliani, L. E., Yuniarta, G. A., \& Sinarwati, K. (2014). Pengaruh Kinerja Keuangan Terhadap Nilai Perusahaan Dengan Pengungkapan Corporate Social Responcibility Dan Good Corporate Governance Sebagai Variabel Pemoderasi (Studi Kasus Di Bursa Efek Indonesia) Pe. E-Journal S1 Ak Universitas Pendidikan Ganesha, 2(1).

Nuriwan. (2018). Pengaruh Kinerja Keuangan Terhadap Nilai Perusahaan yang Dimoderasi oleh Corporate Social Responsibility (CSR) dan Good Corporate Governance (GCG). Jurnal Riset Akuntansi Dan Keuangan, 6(1), 1124.

Nurlela, R., \& Islahuddin. (2008). Pengaruh Corporate Social Responsibility Terhadap Nilai Perusahaan Dengan Prosentase Kepemilikan Manajemen Sebagai Variabel Moderating (Studi Empiris Pada Perusahaan Yang Terdaftar di Bursa Efek Jakarta). Simposium Nasional Akuntansi (SNA) KE XI PONTIANAK, 23 - 24 JULI 2008, (2), 1-27.

Paul, D., \& Barbara, S. (2009). The relationship among board of director characteristics, corporate social performance and corporate financial performance. International Journal of Managerial Finance, 5(4), 407-423. https://doi.org/10.1108/17439130910987558

Prasetyo, A., \& Meiranto, W. (2017). Pengaruh Corporate Social Responsibility Terhadap Kinerja Keuangan Perusahaan Manufaktur Yang Terdaftar Di BEl. Diponegoro Journal of Accounting, 6(3), 1-12.

Riana, T. C., \& Stanly, A. (2014). Pengaruh Penerapan Good Corporate Governance Terhadap Profitabilitas Pada Perusahaan Perbankan Yang Terdaftar Di BEI Periode 2009-2013. ACCOUNTABILITY, 3(1), 77-85. Retrieved from http://ejournal.unsrat.ac.id/index.php/accountability/article/view/4943

Robins, F. (2005). The Future of Corporate Social Responsibility. Asian Business \& Management, 4(2), 95-115. https://doi.org/10.1057/palgrave.abm.9200125

Salvatore, D. (2005). Ekonomi Manajerial dalam Perekonomian Global. Salemba Empat: Jakarta.

Setyapurnama, Y. S., \& Norpratiwi, A. M. V. (2012). Pengaruh corporate governance terhadap peringkat obligasi dan yield obligasi. Jurnal Akuntansi Dan Bisnis, 7(2).

Susanto, A. B. (2009). Reputation-driven corporate social responsibility Pendekatan strategic management dalam CSR. Erlangga: Jakarta

Tandelilin, E. (2010). Portofolio dan Investasi: Teori dan aplikasi. Kanisius.Jakarta

Ulupui, I. G. K. A. (2007). Analisis pengaruh rasio likuiditas, Leverage, Aktivitas, dan Profitabilitas terhadap Return Saham (Studi Pada Perusahaan Makanan dan Minuman Kategori Industri Barang Konsumsi di BEJ). Jurnal IImiah Akuntansi Dan Bisnis, 9(2), 1-20.

Van der Wiele, T., Kok, P., McKenna, R., \& Brown, A. (2001). A Corporate Social Responsibility Audit within a Quality Management Framework. Journal of Business Ethics, 31(4), 285-297. https://doi.org/10.1023/A:1010767001610

Vicente, L. C., Fátima, de S. F., \& Felipe, C. de V. (2011). Corporate social responsibility, firm value and financial performance in Brazil. Social Responsibility Journal, 7(2), 295-309. https://doi.org/10.1108/174711111111141549

Villanueva-Villar, M., Rivo-López, E., \& Lago-Peñas, S. (2016). On the relationship between corporate governance and value creation in an economic crisis: Empirical evidence for the Spanish case. BRQ Business Research Quarterly, 19(4), 233-245. https://doi.org/https://doi.org/10.1016/j.brq.2016.06.002

Wang, H., Lu, W., Ye, M., Chau, K. W., \& Zhang, X. (2016). The curvilinear relationship between corporate social performance and corporate financial performance : Evidence from the international construction industry. Journal of Cleaner Production, 137(August), 1313-1322. https://doi.org/10.1016/j.jclepro.2016.07.184

Yendrawati, R., \& Pratidina, D. (2013). pengaruh Kinerja Keuangan Terhadap Nilai Perusahaan Dengan Corporate Social Reesponsibility dan Kepemilikan Institusional Sebagai Variabel Pemoderasi (Studi Empiris Pada Perusahaan Manufaktur Di Bursa Efek Indonesia). UNISIA, 35(78), 17-24.

www.ilcg.org 